\title{
Synthesis and Characterization of New Polyimide/Organoclay Nanocomposites Containing Benzophenone Moieties in the Main Chain
}

\author{
Khalil Faghihi,* Mostafa Ashouri, and Akram Feyzi \\ Organic Polymer Chemistry Research Laboratory, Department of Chemistry, Faculty of Science, Arak University, 38158-879, \\ Arak, Iran, E-mail: k-faghihi@araku.ac.ir
}

Received October 27, 2012; accepted April 24, 2013

\begin{abstract}
A series of nanocomposites consist of organic polyimide and organo-modified clay content varying from 0 to $5 \mathrm{wt} \%$, were successfully prepared by in situ polymerization. Polyimide used as a matrix of nanocomposite was prepared through the reaction of 1,4-bis [4-aminophenoxy] butane (APB) and 3،3'،4،4'-benzophenone tetra carboxylic dianhydride (BTDA) in $N, N$-dimethylacetamide (DMAc). The resulting nanocomposite films were characterized by FT-IR spectroscopy, X-ray diffraction (XRD), scanning electron microscopy (SEM) and thermogravimetric analysis (TGA).

Key words: Polyimide, nanocomposite, organoclay.
\end{abstract}

\section{Introduction}

Polyimides (PI) are used extensively in microelectronics, optical, automotive and aerospace applications because of their excellent thermal stability and mechanical properties [1]. In particular, the aromatic polyimide has been used as dielectric layers in the multi-chip packaging for semiconductors [2]. Last researches are devoted to further improving the performance of (PIs) in some specific applications [3-5]. In last decades, it was found that the introduction of well dispersed clay layers such as montmorillonite (MMT) into a polymer matrix has been proved to be completely effective in the improvement of mechanical, thermal and barrier properties of the polymers [6-12]. Pure MMT is difficult to mix with hydrophobic polymers due to its nature. It is necessary to modify MMT by replacing the metal cations in the intergallery of silicate layers with various organic cation molecules [13]. The surface modification of the layered silicates increased interlayer spacing and became more uniform after intercalation with organic molecules. This surface treatment with organic molecules made MMT more miscible with polymer molecules. Thus, polymer molecules are allowed to enter the enlarged interlayer of organoclay for further intercalation or exfoliation [14-16]. Different synthesis methods have been proposed to obtain nanocomposites: intercalation of polymer from solution, in situ intercalative polymerization, or melt intercalation.

In the present work, nanocomposites of polyimide and organo-modified clay have been synthesized using in situ polymerization of 1, 4-bis [4-aminophenoxy] butane (APB) and 3،3'،4، '-benzophenone tetra carboxylic dianhydride (BTDA), between the organoclay layeres, through thermal imidization reaction. Nanocomposite films containing 0.5, 1, 3, 5 wt.\% of organoclay obtained by thermal imidization were character-
Resumen. Se preparó una serie de nanocompuestos consistentes en poliimidas y arcillas modificadas con grupos orgánicos, en los que se varió el contenido de arcilla modificada, de 0 a $5 \%$ en peso; La poliimida utilizada como matriz del nanocompuesto se preparó mediante la reacción de 1,4-bis [4-aminofenoxi] butano y el dianhídrido carboxílico 3,3,4,4-tetra benzofenona en $N, N$-dimetilacetamida (DMAC). Las películas de nanocompuestos resultantes se caracterizaron por espectroscopía FT-IR, difracción de rayos X (XRD), microscopía electrónica de barrido y análisis termogravimétrico.

Palabras clave: Poliamida, nanocompuestos, arcilla orgánica.

ized by Fourier-Transform infrared (FTIR) spectroscopy, wideangle powder X-ray diffraction (XRD) and scanning electron microscopy (SEM).

The effects of material composition on thermal stability of pure PI and PCN materials were studied by thermogravimetric analysis (TGA).

\section{Experimental}

\section{Materials}

All chemicals were purchased from Fluka Chemical Co. (Switzerland), Aldrich Chemical Co. (Milwaukee), Merck Chemical Co. (Germany) and Across Organics N.V/S.A (Belgium). MMT, with a cation exchange capacity (CEC) of $95 \mathrm{meq} / 100 \mathrm{~g}$ was supplied and have been modified with 4، '-oxydianiline (ODA) to preparation of nanocomposite films. Diamine (APB) $\left(\mathrm{mp}=152-154{ }^{\circ} \mathrm{C}\right)$ was prepared according to our pervious work [17].

\section{Techniques}

${ }^{1} \mathrm{H}$ NMR and ${ }^{13} \mathrm{C}$ NMR spectra were recorded on a Bruker 300 $\mathrm{MHz}$ instrument (Germany). Fourier transform infrared (FTIR) spectra were recorded on Galaxy series FTIR 5000 spectrophotometer (England). Spectra of solid were performed by using $\mathrm{KBr}$ pellets. Vibration transition frequencies were reported in wave number $\left(\mathrm{cm}^{-1}\right)$. Wide angle XRD study of the samples was performed with an X-ray diffractometer with a copper target at a scanning rate of $4 \% \mathrm{~min}$. The morphologies of the fractured surfaces of the extrusion samples were investigated using a LEO 1455 VP scanning electron microscope (SEM). 
Thermal Gravimetric Analysis (TGA) data for polyimide and nanocomposites were taken on a Perkin-Elmer TG/DTA System under $\mathrm{N}_{2}$ atmosphere at rate of $10{ }^{\circ} \mathrm{C} / \mathrm{min}$ until $800{ }^{\circ} \mathrm{C}$. Thermal process was done on a Memmert vaccum oven.

\section{Synthesis of PEI through thermal imidization}

A typical procedure to prepare polyetherimide (PEI) by thermal imidization was as follows: Amounts of 3،3'،4،4'-benzophenone tetra carboxylic dianhydride $(0.32 \mathrm{~g}, 1 \mathrm{mmol})$ (flask A) and 1,4-bis [4-aminophenoxy] butane $(0.27 \mathrm{~g}, 1 \mathrm{mmol})$ (flask B) were dissolved separately in $1 \mathrm{~mL}$ of DMAc stirring for $1 \mathrm{~h}$ under $\mathrm{N}_{2}$ atmosphere at room temperature. Subsequently, the solution contained in flask A was added to the solution of APB in DMAc (flask B). This reaction mixture was stirred at room temperature for $24 \mathrm{~h}$ to form the poly(amic acid), PAA. The resulting PAA solution was cast onto a petrri-dish, and placed in an oven for a programmed heat treatment: $2 \mathrm{~h}$ at 80 ${ }^{\circ} \mathrm{C}, 2 \mathrm{~h}$ at $110{ }^{\circ} \mathrm{C}, 2 \mathrm{~h}$ at $170{ }^{\circ} \mathrm{C}, 4 \mathrm{~h}$ at $200{ }^{\circ} \mathrm{C}$.

\section{Preparation of ODA-MMT}

Organophilic MMT was prepared by cation exchange of sodium ions within MMT clay with alkylammonium ions of the intercalation agent. Typically, $5 \mathrm{~g}$ of MMT clay with a CEC value of $95 \mathrm{mEq}(100 \mathrm{~g})^{-1}$ was stirred in $600 \mathrm{~mL}$ of distilled water (beaker A) at room temperature overnight. A separate solution containing $1.18 \mathrm{~g}$ of ODA in $30 \mathrm{~mL}$ of distilled water (beaker B) was prepared with the aid of magnetic stirring and the addition of a $1.0 \mathrm{~mol} \mathrm{~L}^{-1} \mathrm{HCl}$ aqueous solution to adjust the $\mathrm{pH}$ value to 3-4. After stirring for $3 \mathrm{~h}$, the protonated amino acid solution (beaker B) was added to the MMT suspension (beaker A) at a rate of approximately $10 \mathrm{~mL} \mathrm{~min}{ }^{-1}$ with vigorous stirring. The mixture was stirred overnight at room temperature. Organophilic MMT was recovered using ultracentrifugation (9000 rpm, $30 \mathrm{~min}$ ) and filtering using a Buchner funnel. The resulting organophilic MMTs were washed and filtered at least four times to remove any excess ammonium ions.

\section{Synthesis of PCNs by in situ polymerization}

A procedure for the preparation of $\mathrm{PCNs}$ by thermal imidization is shown in Scheme 1. An appropriate amount of organophilic MMT (0.5 wt \%, $1 \mathrm{wt} \%, 3 \mathrm{wt} \%$ and $5 \mathrm{wt} \%)$ was dispersed into $3 \mathrm{~g}$ of DMAc with the aid of magnetic stirring for $24 \mathrm{~h}$ under $\mathrm{N}_{2}$ atmosphere at room temperature (flask $\mathrm{A}$ ), and $1 \mathrm{mmol}$ of dianhydride (BTDA) was dissolved into $1.5 \mathrm{~g}$ of DMAc with the aid of magnetic stirring for $30 \mathrm{~min}$ at room temperature (flask B). The solution contained in flask B was poured into flask A and stirred for $24 \mathrm{~h}$ under $\mathrm{N}_{2}$ atmosphere at room temperature. In the separate beaker, $1 \mathrm{mmol}$ of diamine monomer was dissolved in $1.5 \mathrm{~g}$ of DMAc with the aid of magnetic stirring for $30 \mathrm{~min}$ at room temperature (flask C). The content of flask $\mathrm{C}$ was added to the content of flask A + B and was stirred for 24h under $\mathrm{N}_{2}$ atmosphere at room temperature to form a PAA/clay nanocomposite solution. The resulting solution was then cast

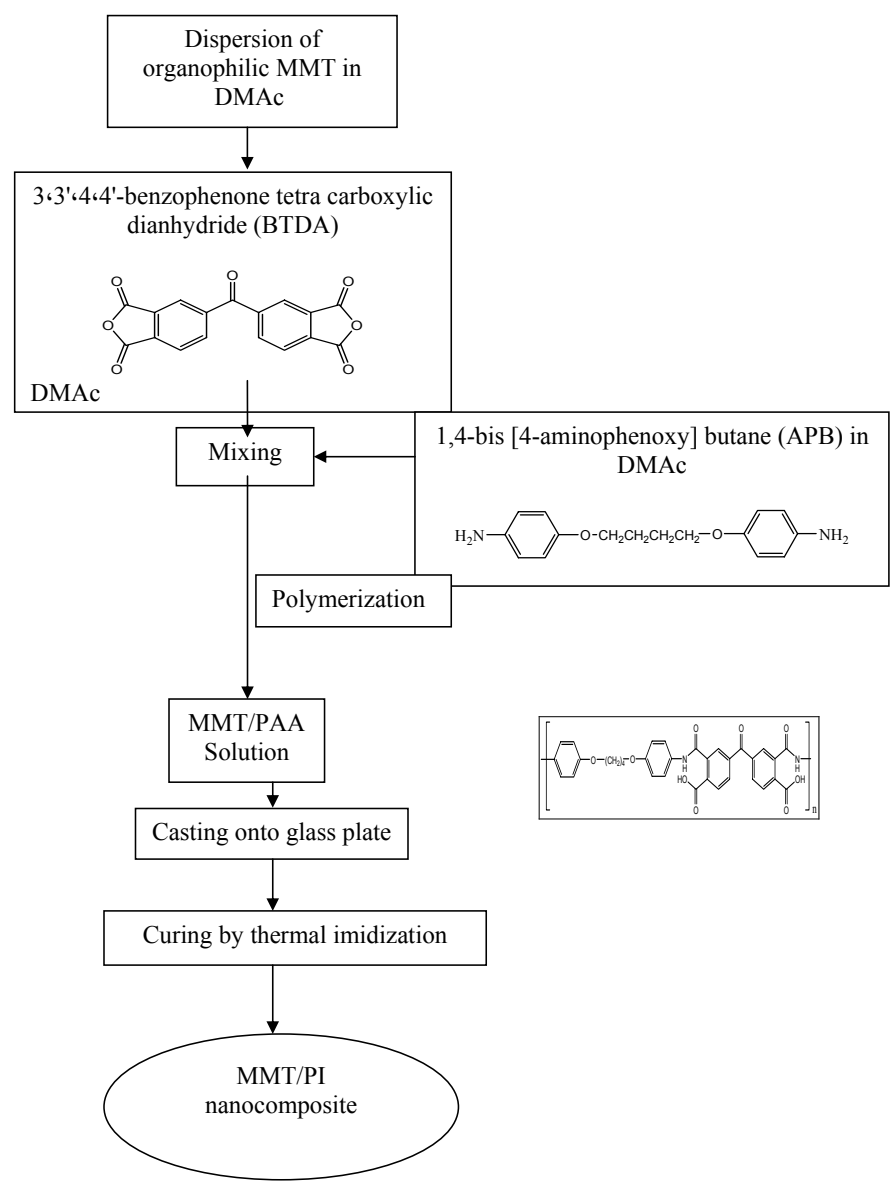

Scheme 1. Synthesis of PCNs.

onto a glass plate, and heat treated in a high temperature oven with the same program as that for the polyimide film.

\section{Results and Discussion}

\section{Characterization}

Figure 1 shows the representative FTIR spectra for organclay (Fig. 1a. ), polyetherimide (Fig. 1b.) and PCN3 (Fig. 1c.), respectively. The spectrum shown in Figure (1b) at $200{ }^{\circ} \mathrm{C}$ is from the polyimide (after imidization). The polyimide prepared from thermal imidization of diamine (APB) and dianhydride (BTDA) exhibited an obvious carbonyl asymmetric stretching of $\mathrm{C}=\mathrm{O}$ located at $1782 \mathrm{~cm}^{-1}$ and symmetric stretching of $\mathrm{C}=\mathrm{O}$ located at $1718 \mathrm{~cm}^{-1}$ in imide groups, and the band at $1377 \mathrm{~cm}^{-}$ ${ }^{1}$, which is characteristic of C-N stretching in imide groups, and the band at $715 \mathrm{~cm}^{-1}$, which is characteristic of $\mathrm{C}=\mathrm{O}$ bending in imide groups, respectively.

Figure (1a and 1c) shows the FTIR spectra for organoclay and PCN3. The characteristic vibration bands of organoclay are shown at $1047 \mathrm{~cm}^{-1}$ (Si-O), $526 \mathrm{~cm}^{-1}$ (Al-O) and 462 $\mathrm{cm}^{-1}(\mathrm{Mg}-\mathrm{O})$, and the characteristic vibration bands of PCN3 with the same as that for the polyimide, only different there 


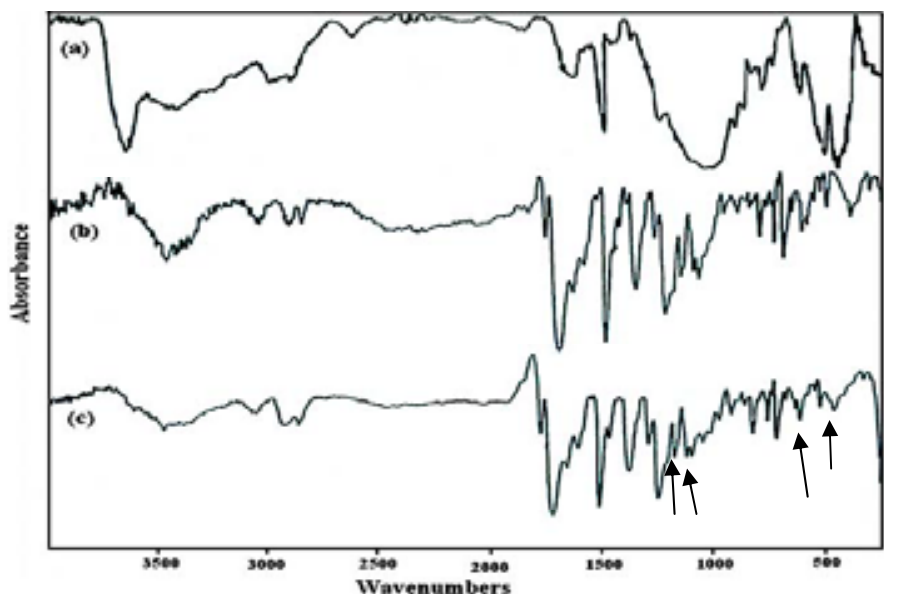

Fig. 1. FT-IR spectra of (a) MMTclay, (b) pure PEI and (c) PCN 3.

was a peak appearing at $1097 \mathrm{~cm}^{-1}(\mathrm{Si}-\mathrm{O})$. This indicates that organoclay layers disperse in polyimide.

\section{X-ray diffraction (XRD)}

Figure 2 illustrates the wide-angle powder XRD patterns of clay, organoclay and a series of PCN materials. Raw clay was found to show a diffraction peak at $2 \theta=9.3^{\circ}(d$-spacing: 1.05 $\mathrm{nm})$. For organoclay, this peak shifted to $2 \theta=6.6^{\circ}$ ( $d$-spacing: $1.34 \mathrm{~nm}$ ) that indicate spacing between silicate layers have been increased. For PCNs there were a diffraction peak at $2 \theta=$ $3.5^{\circ}$ implying the possibility of interclated organoclay platelets embedded in the PI matrix. As shown in Figure 2, the peak appeared at $6.8^{\circ}$ ( PCN5) indicates that there may be a small amount of organoclay that cannot be interclated in PI and exists in the form of an agglomerated layer structure.

\section{Scanning electron microscopy (SEM)}

In the SEM Figure $3 a, 3 b$ and $3 c$, shows clay phases within the nanocomposite films with organoclay contents of $0.5 \%, 3 \%$ and $5 \%$. The PCN0.5 was well dispersed in a continuous PI phase (Fig. 3a.). In contrast, the PCN3 (Fig. 3b.), shows some deformed regions that can be attributed to the coarseness of the fractured surface. A comparison of the micrographs reveals that the fractured surfaces of the hybrid films with higher clay contents were more deformed than those of the films with low clay contents, likely because of the agglomeration of clay particles.

\section{Thermogravimetric analysis (TGA)}

Thermal stability of the nanocomposites was determined by thermogravimetric technique under $\mathrm{N}_{2}$ atmosphere at a heating rate of $10{ }^{\circ} \mathrm{C} \mathrm{min}^{-1}$. Thermograms obtained for these materials are shown in Figure 4. The TGA results of PEI, PCN1 and PCN5 are summarized in Table 1. The increase in char yield and thus thermal stability of these hybrids with an increasing clay loading was likely due to two factors [18]: (1) the signifi-

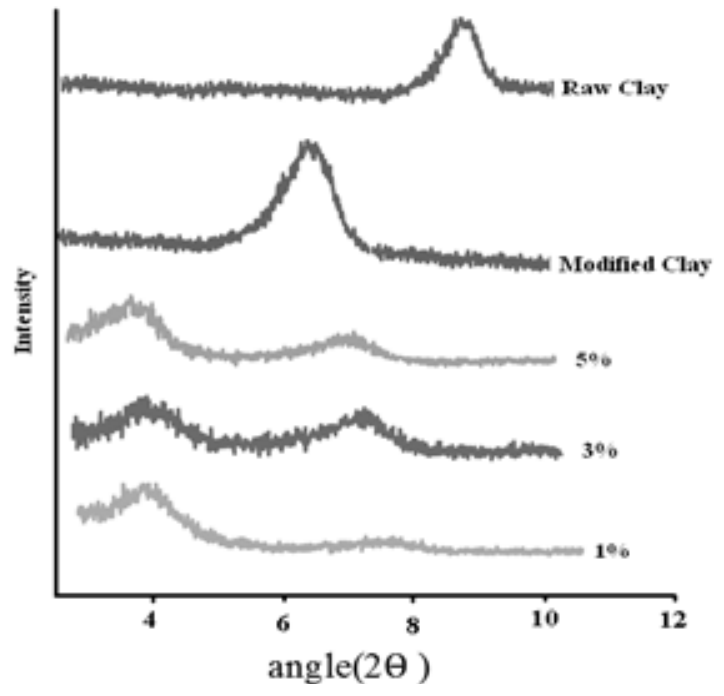

Fig. 2. Wide-angle powder X-ray diffraction patterns for PCN1, PCN3, PCN5, Organoclay and MMT/Na ${ }^{+}$.

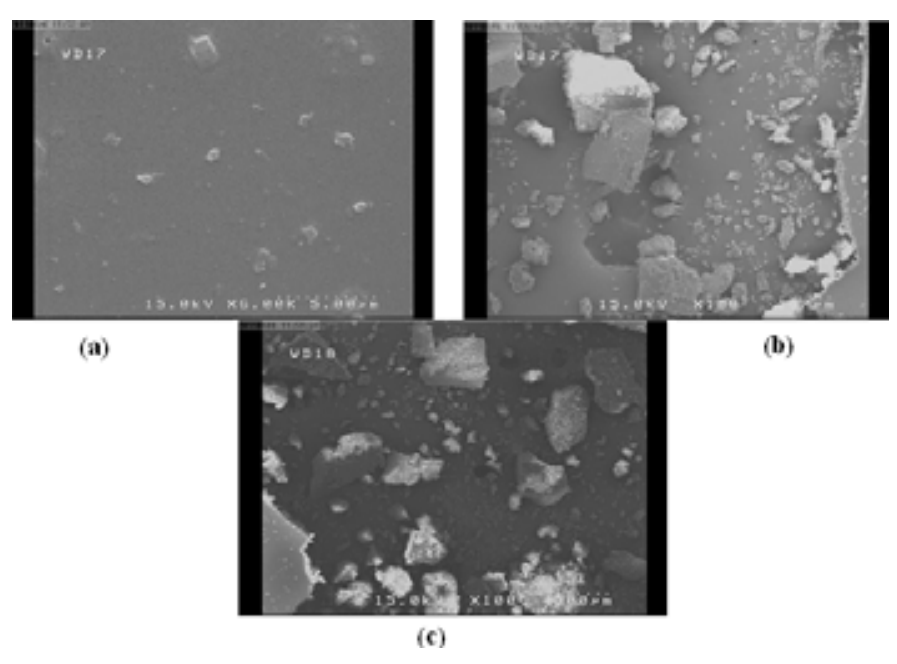

Fig. 3. Scanning electron micrograph image for (a) PCN 0.5, (b) PCN 3 and (c) PCN 5.

cant effect of small amounts of dispersed clay layers on the free volume of the PI and (2) the confinement of intercalated polymer chains within the clay galleries, which prevented the segmental motions of the chains. Similar results have been obtained in other studies of polymer nanocomposites [19, 20].

Thermal decomposition temperatures of the PEI, PCN1 and PCN5 are between $350-450{ }^{\circ} \mathrm{C}$. TGA results indicated that these materials were found thermally stable, which increases with the addition of clay content in the polymer matrix. This increase PCN1 in the thermal stability may result from the high thermal stability of organoclay network and the physical crosslink points of the organoclay particles, which limited the movement of the molecular chain of polymer. PCN5 thermal stability decrease a little in beginning, because of agglomeration of organoclay particles. The weight retained by these samples at $800{ }^{\circ} \mathrm{C}$ was roughly proportional to the amount of organoclay 
Table 1. Thermal behavior of PEI, PCN1 and PCN5.

\begin{tabular}{|c|c|c|c|c|c|c|}
\hline \multirow[b]{2}{*}{ Compound } & \multicolumn{2}{|c|}{$\begin{array}{c}\text { Feed Composition } \\
(\mathrm{Wt} \%)\end{array}$} & \multicolumn{4}{|c|}{$\begin{array}{c}\text { Thermal Properties } \\
\left({ }^{\circ} \mathrm{C}\right)\end{array}$} \\
\hline & PEI & MMT & $\mathrm{T}_{5}\left({ }^{\circ} \mathrm{C}\right)^{\mathrm{a}}$ & $\mathrm{T}_{10}\left({ }^{\circ} \mathrm{C}\right)^{\mathrm{b}}$ & Char yield $(\%)^{\mathrm{c}}$ & $\mathrm{LOI}^{\mathrm{d}}$ \\
\hline PCN1 & 99 & 1 & 420 & 448 & 44.9 & 35.4 \\
\hline PCN5 & 95 & 5 & 300 & 430 & 48.1 & 36.7 \\
\hline
\end{tabular}

a,b Temperature at which $5 \%$ or $10 \%$ weight loss was recorded TGA at a heating rate of $10^{\circ} \mathrm{C} / \mathrm{min}$ in $\mathrm{N}_{2}$. ${ }^{\mathrm{c}}$ Weight percentage of material left after TGA analysis at maximum temperature $800^{\circ} \mathrm{C}$ in $\mathrm{N}_{2}$.

d Limiting Oxygen Index.

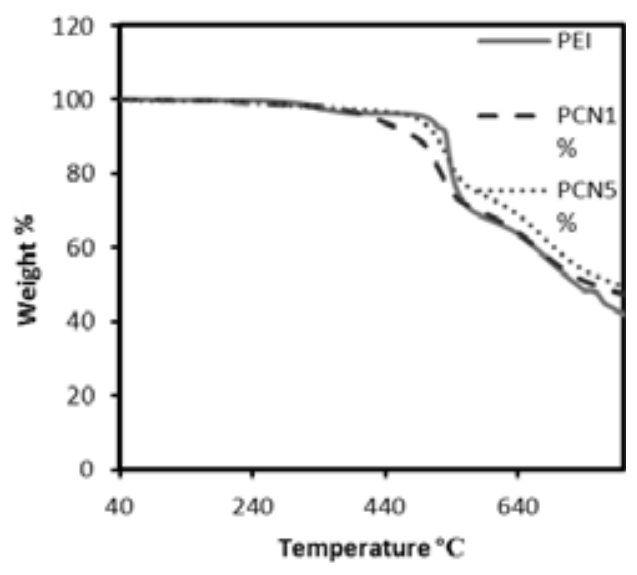

Fig. 4. TGA thermograms of PEI, PCN 1 and PCN 5.

in the nanocomposites. Organoclay was found to increase the thermal stability presumably due to superior insulating characteristics of the layered silicate acting as mass transport barrier to the volatile products generated during decomposition. The char yield can be a decisive factor to estimaite the limited oxygen index (LOI) of PEI, PCN1 and PCN5 according to the Van Krevelen-Hoftyzer's equation [21]:

$$
\mathrm{LOI}=17.5+0.4 \mathrm{CR}
$$

That CR is the char yield. Polyimide, PCN1 and PCN5 had LOI values $31,35.4$ and 36.7 respectively, which were calculated from their char yield. On the basis of the LOI values such macromolecules can be classified as self-extinguishing polyimide and PCNs.

\section{Conclusions}

A series of PEI and PCNs consisting of organoclay were prepared by effectively dispersing the organoclay in an organic PEI matrix by an in situ polymerization. The synthesized PEI and PCNs were characterized by FTIR, wide-angle powder XRD and SEM. The effects of material composition on thermal stability of PEI and PCNs, were studied by TGA curves. Dispersal of organoclay into the PEI matrix was found to boost the thermal stability, as by the enhancement of thermal properties of the PEI based on the TGA studies.

\section{References}

1. Nah, C.; Han, S.H.; Lee, J.H.; Lee, M.H.; Lim, S.D.; Rhee, J. Composites: Part B. 2004, 35, 125-131.

2. Zhang, Y.H.; Dang, Z.M.; Fu, S.Y.; Xin, J.H.; Deng, J.G.; Wu, J.; Yang, S.; Li, L.F.; Yan, Q. Chem. Phys. Lett. 2005, 401, 553557.

3. Saito, J.; Miyatake, K.; Watanabe, M. Macromolecules 2008, 41, 2415-2420.

4. Neyertz, S.; Brown, D. Macromolecules 2008, 41, 2711-2721.

5. Mensitieri, G.; Lavorgna, M.; Larobina D.; Scherillo, G.; Ragosta, G.; Musto, P. Macromolecules 2008, 41, 4850-4855.

6. Giannelis, E.P.; Krishnamoorti, R.; Manias, E. Adv. Polym. Sci. 1999, 138, 107.

7. Choi, Y.S.; Choi, M.H.; Wang, K.H.; Kim, S.O.; Kim, Y.K.; Chung, I.J. Macromolecules 2001, 34, 8978.

8. Agag, T.; Koga, T.; Takeichi, T. Polymer 2001, 42, 3399.

9. Liang, Z.M.; Yin, J.; Xu, H.J. Polymer 2003, 44, 1391.

10. Yono, K.; Usuki, A.; Okada, A.; Kurauchi, T.; Kamigaito, O. J. Polym. Sci. Part A, Polym. Chem. 1993, 31, 2493.

11. Lu, Q.H.; Yin, J.; Xu, H.J.; Zhang, J.; Sun, L.M.; Zhu, Z.K. J. Appl. Polym. Sci. 1999, 72, 1299.

12. Bharadwaj, R.K. Macromolecules 2001, 34, 9189.

13. Tyan, H.L.; Leo, C.M.; Wei, K.H. Chem. Mater. 2001, 13, 22.

14. Cho, M.H.; Choi, K.T. Macromol. Rapid. Commun. 1998, 19, 271-273.

15. Cho, M.; Choi, H.; Ahn, W. Langmuir 2004, 20, 202-207.

16. Cho, M.; Cho, Y.; Choi, H.; Jhon, M. Langmuir 2003, 19, 58755881.

17. Faghihi Kh.; Shabanian, M.; Hajibeygi M.; Mohammadi Y. Polym. Bull. 2011, 66,37-49.

18. Li, F.; Ge, J.; Honigfort, P.; Fang, S.; Chen, J.C.; Harris, F.; Cheng, S. Polymer 1999, 40, 4987-5002.

19. Agag, A.; Takeichi, T. Polymer 2000, 41, 7083-7090.

20. Mallakpour, S.; Rafiee, Z. Polymer 2008, 49, 3007-3013.

21. Van Krevelen, D. W.; Hoftyzer, P. J. Properties of polymer. Elsevier Scientific Publishing Company, 1976, New York. 